\title{
Nepal: Support communication to enhance young mothers' reproductive health
}

Frontiers in Reproductive Health

Follow this and additional works at: https://knowledgecommons.popcouncil.org/departments_sbsr-rh How does access to this work benefit you? Let us know!

\section{Recommended Citation}

"Nepal: Support communication to enhance young mothers' reproductive health," FRONTIERS OR Summary. Washington, DC: Population Council, 2005. 
Nepal

Community Involvement OR Summary 51

\section{Support Communication to Enhance Young Mothers' Reproductive Health}

\section{Communication-based support to mothers'groups and newly formed youth communication groups improved reproductive health knowledge and behavior among young married women in Nepal.}

\section{Background}

From 2000 to 2003, FRONTIERS supported a study by the Center for Research on Environment, Health, and Population Activities (CREHPA) to test communication-based models for improving young couples' access to and use of reproductive health information and services in the Udaypur district of eastern Nepal. The 14-month intervention, undertaken as part of a reproductive health project implemented by the Nepal Red Cross Society (NRCS) and the Center for Development and Population Activities (CEDPA), sought to improve social norms that leave young women vulnerable to health risks related to early marriage and childbearing and limited access to reproductive health services.

The study compared two experimental models with two control groups. In the experimental models, information, education, and communication (IEC) materials were provided for: (1) "youth communication action groups," formed in ten village development committees (VDCs) made of young married women under the age of 25; and (2) existing or reactivated village mothers' groups in ten VDCs made of women aged 15-49 (formed as part of government health services). The two experimental groups received training, assistance with group interaction, outreach, and educational materials about sexually transmitted infections (STIs) and condom use. Members of both groups met monthly and were encouraged to organize special events such as health fairs, talk programs, and educational events for husbands.
Researchers administered surveys to young married women in both the control and experimental sites before and after the intervention.

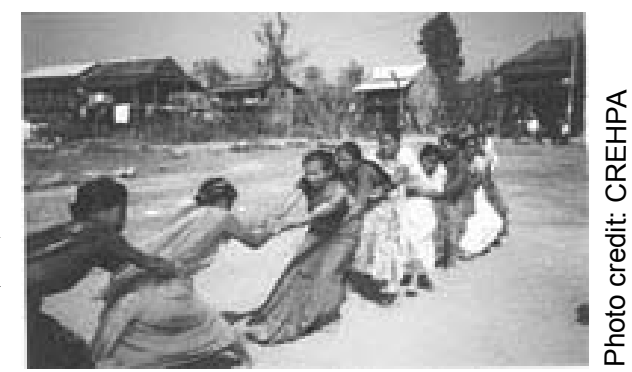

Women's groups sponsored special events to increase health awareness.

\section{Findings}

- The young women's knowledge of family planning was high at baseline and increased in the experimental and control groups. Knowledge of three temporary methods (condoms, pills, and the injectable) increased significantly following the intervention, becoming nearly universal in the experimental youth groups (96\%) and mothers' groups (94\%) as compared to the control groups $(83 \%)$. Knowledge of the correct use of pills and the injectable also increased significantly in the intervention areas.

- The contraceptive prevalence rate (CPR) increased in all three areas following the intervention, but the increase was much greateralmost double - in the area of the mothers' groups (from $19 \%$ to $37 \%$ ), relative to the modest increases in the youth group area (26\% to $28 \%$ ) and the control area (29\% to $34 \%)$. In all groups, the main reasons for not using a family planning method were postpartum or breastfeeding status, desire for another child, and the husband's absence. 
- Knowledge of safe pregnancy practices increased in all three areas, but many gaps remain. Women generally knew that antenatal care checkups were recommended, but one-third or less knew the recommended frequency of visits (four). Knowledge on nutrition during pregnancy improved only among the youth groups.

Despite limitations to knowledge, safe motherhood practices improved significantly in all three areas. Improvements were more pronounced in the experimental areas relative to the control areas (see Table).

- Knowledge about sexually transmitted infections (STIs) including HIV/AIDS increased significantly in both experimental and control areas, with the greatest increases among the youth groups, followed by the mothers' groups.

Following the intervention, significantly more women in the experimental youth groups $(89 \%)$ and in the mothers' groups $(35 \%)$ could name two or more risk factors for HIV/AIDS, while the increase was moderate in the control group.

- Community awareness of outreach activities increased significantly in the experimental areas, while gains in the control group were modest. About 80 percent of respondents in the experimental areas had heard of or participated in group activities following the intervention. At least half of respondents in these areas had received counseling on such topics as incomegenerating strategies, negotiating condom use with husbands, and care and immunization for newborns.

\section{Utilization}

The mothers' group model has been adopted in another district by a CREHPA associate organization in western Nepal.

\section{Policy Implications}

- The rapid uptake of educational material by both experimental groups - particularly given the conflict in the region during the study - suggests that communication-based models are appropriate in this setting. Both models are suitable for replication in Nepal.

\section{Indicators of Safe Motherhood practices in experimental and control areas before and after the intervention (\%)}

\begin{tabular}{|l|c|c|c|c|c|c|}
\hline & \multicolumn{2}{|c|}{ Youth groups } & \multicolumn{2}{c|}{ Mothers' groups } & \multicolumn{2}{c|}{ Control groups } \\
\hline Indicator & Baseline & Endline & Baseline & Endline & Baseline & Endline \\
\hline Received any ANC & 52 & $76^{*}$ & 20 & $54^{*}$ & 45 & $59^{*}$ \\
\hline $\begin{array}{l}\text { Attended four or more } \\
\text { ANC visits }\end{array}$ & 25 & $53^{*}$ & 16 & 21 & 20 & 27 \\
\hline Received 2 TT injections & 51 & $75^{*}$ & 25 & $43^{*}$ & 47 & $67^{*}$ \\
\hline $\begin{array}{l}\text { Deliveries assisted by } \\
\text { trained birth attendants }\end{array}$ & 14 & $43^{*}$ & 10 & $26^{*}$ & 17 & $32^{*}$ \\
\hline Consumed Vitamin A & 42 & $63^{*}$ & 16 & $28^{*}$ & 34 & $42^{*}$ \\
\hline Consumed iron tablets & 16 & $57^{*}$ & 9 & $25^{*}$ & 12 & $36^{*}$ \\
\hline
\end{tabular}

* $\mathrm{p} \leq .05 \quad$ \#TT $=$ tetanus toxoid

Source: Center for Research on Environment, Health, and Population Activities (CREHPA). 2005. "Determining an effective and replicable communication-based mechanism for improving young couples' access to and use of reproductive health information and services in Nepal - An operations research study," FRONTIERS Final Report. Washington, DC: Population Council. Available on our website at www.popcouncil.org/frontiers/frontiersfinalrpts.html or by e-mail:frontiers@pcdc.org

This project was conducted with support from the U.S. AGENCY FOR INTERNATIONAL DEVELOPMENT under Cooperative Agreement Number HRN-A-00-98-00012-00. 